\title{
Tetanus and Diphtheria Toxoids Adsorbed
}

National Cancer Institute

\section{Source}

National Cancer Institute. Tetanus and Diphtheria Toxoids Adsorbed. NCI Thesaurus.

Code C96405.

A sterile, intramuscular suspension of alum (aluminum potassium sulfate)-precipitated toxoids indicated for active immunization for the prevention of tetanus and diphtheria for use in persons 7 years of age or older. 